\title{
Heightened risk of cardiac events following percutaneous coronary intervention for cocaine-associated myocardial infarction
}

\author{
Ching Wei Russell Chen ${ }^{1}$, Mohammed Makkiya ${ }^{1}$, Wilbert Aronow ${ }^{2}$, Daniel M. Spevack ${ }^{2}$
}

\begin{abstract}
${ }^{1}$ Division of Cardiology, Department of Medicine, Montefiore Medical Centre, Albert Einstein College of Medicine, Bronx, New York, USA

${ }^{2}$ Division of Cardiology, Department of Medicine, Westchester Medical Centre, New York Medical College, Valhalla, New York, USA
\end{abstract}

Submitted: 10 August 2018

Accepted: 30 November 2018

Arch Med Sci 2020; 16 (1): 66-70

DOI: https://doi.org/10.5114/aoms.2020.91287

Copyright $\odot 2019$ Termedia \& Banach

\section{Abstract}

Introduction: Several works have suggested heightened risk for cardiac events in cocaine users following percutaneous coronary intervention $(\mathrm{PCl})$. Such studies have generally been performed in small, poorly defined samples and have not utilised optimal control groups. We aimed to define the short-term risk for death or recurrent myocardial infarction (MI) when $\mathrm{PCl}$ was performed for myocardial infarction in subjects presenting with urine toxicology positive for cocaine in relation to subjects testing negative for cocaine use.

Material and methods: Our institutional electronic health record (EHR) was queried for all subjects with urine toxicology performed for cocaine exposure within 5 days before or after having elevated troponin-T assay between $1 / 1 / 08$ and $12 / 31 / 13$. Query results were cross-referenced with our institutional cardiology database to identify the sample who had $\mathrm{PCl}$ on the same admission as the cocaine test. Subsequent readmission for $\mathrm{MI}$ was assessed from the EHR, and deaths were identified from the National Death Index.

Results: $\mathrm{PCl}$ had been performed in 380 subjects who tested negative for cocaine and 44 subjects who tested positive. In the cocaine-positive group, incidences of death or $\mathrm{MI}$ at 30 days and 1 year were $18 \%$ and $23 \%$, respectively. Those who tested positive for cocaine had increased odds (odds ratio $(\mathrm{OR})=2.3,95 \%$ confidence interval $(\mathrm{Cl}): 1.0-5.1, p=0.04)$ for death or $\mathrm{MI}$ at 30 days post $\mathrm{PCl}$, after adjustment for age, sex, prior $\mathrm{MI}$, and comorbidity index. Although the odds for events 1 -year post $\mathrm{PCl}$ were not increased $(\mathrm{OR}=2.0,95 \% \mathrm{Cl}: 0.9-4.3)$, the $p$-value approached significance in this small sample $(p=0.09)$.

Conclusions: This retrospective study suggests that $\mathrm{PCl}$ performed in cocaine-associated myocardial infarction comes with a high 30-day and oneyear risk. Further prospective studies are needed to better define this risk and to lend insight into better management strategies.

Key words: percutaneous coronary intervention, cocaine, acute myocardial infarction.

\section{Introduction}

Cocaine is the recreational drug that leads to the most emergency department visits in the United States [1], and its use is associated with a number of cardiovascular emergencies, including chest pain and myo-

\author{
Corresponding author: \\ Daniel M. Spevack MD \\ Westchester Medical Centre \\ 100 Woods Road \\ Valhalla \\ New York 10595, USA \\ Phone: 914-493-7199 \\ E-mail: Daniel.spevack@ \\ wmchealth.org
}


cardial infarctions (MI) [2-5]. Cocaine use leads to early atherosclerosis, increased coronary spasm, increased platelet aggregation, increased oxygen demand of myocardium, and severe hypertension [6-13], all of which may contribute to the pathogenesis of $\mathrm{Ml}$ and present unique challenges for management.

Although percutaneous coronary intervention $(\mathrm{PCl})$ is currently recommended as the primary treatment for acute coronary syndrome and high-risk chest pain associated with cocaine use [14], multiple studies have reported increased incidence of early stent thrombosis, and the safety of this approach has therefore been questioned [15-19]. In this study we aim to better define, as our primary outcome, the short-term (30-day) and intermediate-term (1-year) risk for death or recurrent $\mathrm{MI}$ when $\mathrm{PCl}$ was performed for patients presenting with cocaine-associated MI.

\section{Material and methods}

Our institutional electronic health record (EHR) was queried for all subjects presenting with suspected myocardial infarction between January 1 , 2004 to December 31, 2013. We included only those with urine toxicology testing for cocaine exposure performed within the five days before or after myocardial infarction, as demonstrated by elevated troponin-T assay value above $0.2 \mathrm{ng} / \mathrm{ml}$. Query results were cross-referenced with our institutional cardiology database to identify the patients who had $\mathrm{PCl}$ on the same admission as the cocaine test. A total of 2861 patients were identified who met the inclusion criteria, of whom 424 received $\mathrm{PCl}$. Information about the type of stent implanted was extracted from each catheterisation procedure report. Patient demographics, discharge medications, and comorbidities were obtained from our EHR. These data were collected using the proprietary institution platform Clinical Looking Glass (CLG) (Montefiore-IT, Yonkers, NY), which extracts data from all inpatient and outpatient visits across a multi-hospital and complex ambulatory care network.

Patient outcomes were also assessed using CLG, which is linked to the National Death Index and also captures deaths occurring within our hospital network. Dates for re-admission occurring for MI were also queried from CLG on the basis of diagnosis coding.

We compared the incidence of recurrent $\mathrm{MI}$ and death within 30 days of initial MI. Subsequent readmission for $\mathrm{MI}$ was assessed from the EHR and defined by any admission with myocardial infarction as a diagnosis. Deaths were identified from the National Death Index. The study was approved by the Institutional Review Board of Albert Einstein College of Medicine.

\section{Statistical analysis}

Statistical analysis was done using Stata software, version 11.2 (College Station, TX). Normally distributed data were presented as the mean \pm standard deviation (SD). Non-normal data were presented as the median (interquartile range (IR)). Comparison of means was performed using the two-sample $t$-test. Comparison of categorical data was performed using the $\chi^{2}$ test. Comparison of medians was performed using the Mann-Whitney or Kruskal-Wallis test as appropriate. $P$-values were considered significant if $<0.05$.

Multiple logistic regression was used to assess for excess risk of the primary outcome associated with cocaine exposure. Adjustments were made for age, sex, race/ethnicity, Charlson comorbidity index, prior $\mathrm{PCl}$, and $\mathrm{LV}$ ejection fraction at presentation.

\section{Results}

$\mathrm{PCl}$ had been performed in 380 subjects who tested negative for cocaine and 44 subjects who tested positive. The median number of days between toxicology and $\mathrm{PCl}$ was 0.64 (range: -2.2 , 1.2). Baseline characteristics, comorbidities, catheterisation data, and pharmacotherapy use are shown in the Table I. There were no significant differences in demographics and comorbidity compared to those who were cocaine negative. Compared to the control group, the cocaine-positive patients were less likely to have drug-eluting stents placed and were less likely to receive $\beta$-blockers. No difference was seen in the coronary territories that received $\mathrm{PCl}$.

Those who tested positive for cocaine at the admission for $\mathrm{PCl}$ had increased odds for death or $\mathrm{Ml}$ at 30 days post $\mathrm{PCl}$ (odds ratio $(\mathrm{OR})=2.3,95 \%$ confidence interval $(\mathrm{Cl})$ : $1.0-5.1, p=0.04)$, after adjustment for age, sex, prior MI, and comorbidity index. This association remained significant after adjustment for dual antiplatelet use, $\beta$-blocker use, and/or use of drug-eluting stents. Although the odds for events 1-year post $\mathrm{PCl}$ were not increased $(\mathrm{OR}=2.0,95 \% \mathrm{Cl}: 0.9-4.3)$, the $p$-value approached significance in this small sample $(p=0.09)$.

In the group that tested negative for cocaine at the index admission for $\mathrm{PCl}$, there were 16 additional subjects who tested positive for cocaine at another time, either prior to or after the index admission, resulting in 60 total subjects that ever tested positive for cocaine. These subjects had increased odds for death or $\mathrm{Ml}$ at 30 days post $\mathrm{PCl}(\mathrm{OR}=2.3,95 \% \mathrm{Cl}: 1.1-4.7, p=0.02)$. This association remained significant at 1 -year follow-up $(\mathrm{OR}=2.3,95 \% \mathrm{Cl}: 1.2-4.4, p=0.01)$.

Stent thrombosis was reported to have occurred in 14 of the 56 myocardial infarctions that 
Ching Wei Russell Chen, Mohammed Makkiya, Wilbert Aronow, Daniel M. Spevack

Table I. Patient demographics, comorbidities and catheterization data stratified by cocaine use

\begin{tabular}{|c|c|c|c|c|}
\hline Parameter & Study population & Cocaine positive & Cocaine negative & $P$-value \\
\hline Number of subjects & 424 & 44 & 380 & \\
\hline \multicolumn{5}{|l|}{ Demographics: } \\
\hline Age [years] & $51 \pm 11$ & $53 \pm 9$ & $51 \pm 11$ & 0.15 \\
\hline Male (\%) & 82 & 85 & 82 & 0.59 \\
\hline $\mathrm{BMI}\left[\mathrm{kg} / \mathrm{m}^{2}\right]$ & $29 \pm 5$ & $29 \pm 5$ & $29 \pm 5$ & 0.85 \\
\hline Black (\%) & 24 & 31 & 23 & 0.21 \\
\hline Hispanic (\%) & 48 & 56 & 47 & 0.23 \\
\hline White (\%) & 16 & 10 & 17 & 0.19 \\
\hline Asian/other (\%) & 12 & 4 & 13 & 0.06 \\
\hline \multicolumn{5}{|l|}{ Comorbidities (\%): } \\
\hline Prior MI & 3 & 2 & 3 & 0.69 \\
\hline Prior revascularization & 9 & 13 & 8 & 0.20 \\
\hline Charlson comorbidity score & 3.0 & 3.2 & 3.0 & 0.61 \\
\hline Diabetes & 24 & 23 & 24 & 0.89 \\
\hline Hypertension & 54 & 58 & 54 & 0.62 \\
\hline COPD & 13 & 17 & 12 & 0.30 \\
\hline Renal disease & 7 & 8 & 7 & 0.82 \\
\hline Liver disease & 3 & 7 & 3 & 0.08 \\
\hline HIV & 2 & 2 & 2 & 0.91 \\
\hline Psychiatric disease & 9 & 9 & 9 & 0.81 \\
\hline \multicolumn{5}{|l|}{ Catheterization (\%): } \\
\hline Ejection fraction & 49 & 48 & 49 & 0.53 \\
\hline Drug eluting stent & 45 & 21 & 48 & $<0.001$ \\
\hline Bare metal stent & 44 & 63 & 42 & 0.003 \\
\hline Balloon only & 10 & 15 & 10 & 0.21 \\
\hline \multicolumn{5}{|l|}{ Pharmacotherapy (\%): } \\
\hline Dual antiplatelet & 76 & 83 & 75 & 0.24 \\
\hline$\beta$-blocker & 77 & 60 & 80 & 0.001 \\
\hline \multicolumn{5}{|l|}{$\mathrm{PCl}$ vessels (\%): } \\
\hline Left anterior descending & 43 & 45 & 43 & 0.77 \\
\hline Left circumflex & 27 & 25 & 27 & 0.74 \\
\hline Right coronary & 33 & 32 & 33 & 0.91 \\
\hline Left main & 1 & 0 & 1 & 0.49 \\
\hline
\end{tabular}

were seen in the first year of follow-up. At 5-year follow-up stent thrombosis was noted in 40 individuals. Amongst those who had ever tested positive for cocaine, there was increased odds for stent thrombosis at 5 -year follow-up $(\mathrm{OR}=2.6$, $95 \% \mathrm{Cl}: 1.2-5.5, p=0.01)$.
In both univariate and multivariate analyses, use of dual antiplatelet therapy was associated with reduced odds of events at 30 days, whereas use of drug-eluting stents and use of $\beta$-blockers were not associated with the event rate. Neither use of $\beta$-blockers nor use of drug-eluting stents 
was associated with increased risk for events in those who tested positive for cocaine.

\section{Discussion}

The main finding of our study is that when $\mathrm{PCl}$ is performed in subjects with cocaine-associated myocardial infarction, the risk for recurrent infarction and death is more than $20 \%$ in the first year. In the short-term, the adjusted odds for events was more than double that of those who tested negative for cocaine. Adjustment for use of dual antiplatelet therapy did not mitigate this risk. Although we did not find a statistically significant difference in the 1-year rate of death or recurrent infarction between our study groups, we suspect that this result may be due to our small sample size because the unadjusted 1-year event rate was quite high and the $p$-value was nearing significance. It is notable that the risk for events at 30 days and 1 year were also increased for those who had ever used cocaine, even if they did not test positive for cocaine at the index admission. This suggests that risk for events is related to chronic cocaine use and is not necessarily the result of $\mathrm{PCl}$ being performed while cocaine was positive for cocaine.

We also found a high rate of late stent thrombosis in those who had ever tested positive for cocaine. Several prior studies have suggested increased risk of stent thrombosis in those undergoing PCl for cocaine associated coronary syndromes [15-18]. Prior works, however, have used control groups that did not necessarily test negative for cocaine. We chose a control group that tested negative for cocaine for several different reasons. Most obviously, the negative test serves as fairly good evidence that the infarction and $\mathrm{PCl}$ did not occur while exposed to cocaine. Another reason we chose this control group was to help adjust for hidden confounders. We suspected that those who are tested for cocaine in the first place are a fundamentally different population than those who have not been tested for cocaine at all. To that point, we did find that those in the cocaine-negative group had a $4 \%$ prevalence of prior cocaine use and $22 \%$ prevalence of prior drug abuse.

Our study found a low use of $\beta$-blockers and drug-eluting stents in the group who tested positive for cocaine. Historically, $\beta$-blockers were felt to be potentially harmful in the setting of cocaine intoxication due to the effects of blocked $\beta$-receptors and unopposed stimulated alpha receptors causing pharmacologically induced vasospasm [11]. It is likely that the low use of $\beta$-blockers was influenced by this rationale. Amongst those who tested positive for cocaine, however, we found no evidence for harm with $\beta$-blocker usage compared to those who did not receive them. The extremely low use of drug-eluting stents in the cocaine-positive group may have similarly been influenced by reports of increased stent thrombosis and risk of non-adherence to dual antiplatelet therapy amongst those with cocaine intoxication [1518]. Similarly, we did not find evidence for either benefit or harm with use of drug-eluting stents amongst those who tested positive for cocaine.

Our study has a few important limitations. The study was retrospective and observational, using a study cohort obtained from our electronic health record. This design makes commentary on causality impossible and introduces a potential for unrecognised confounders to be responsible for our result. There are many factors that influenced the decision of our subjects to use cocaine and the decision of the treating physicians to perform $\mathrm{PCl}$. These were certainly not random assignments. Adjusting for demographics and comorbidities may not be enough to account for important unrecognised factors. It is fair to suspect that those in the cocaine group may be more likely to continue cocaine use and are potentially less compliant with prescribed medications. We still do not know if performing $\mathrm{PCl}$ in this setting lowers or increases a patient's risk for future events. Another limitation was that the data were gathered over a 6-year period, during which there have been numerous advancements and changes to stent technology as well as antiplatelet agents. This may affect the generalisability of our results in a more modern population.

In conclusion, our retrospective data suggest that $\mathrm{PCl}$ performed in cocaine associated myocardial infarction comes with high short- and longterm risk. Further prospective studies are needed to better define this risk and to lend insight into better management strategies.

\section{Conflict of interest}

The authors declare no conflict of interest.

\section{References}

1. Substance Abuse and Mental Health Services Administration, Office of Applied Studies. Emergency Department Trends From the Drug Abuse Warning Network, Final Estimates 1995-2002. DAWN Series: D-24, DHHS Publication No. (SMA) 03-3780. Rockville, Md: US Department of Health and Human Services; 2003.

2. Hollander JE, Hoffman RS, Gennis P, et al. Prospective multicenter evaluation of cocaine-associated chest pain. Cocaine Associated Chest Pain (COCHPA) Study Group. Acad Emerg Med 1994; 1: 330-9.

3. Coleman DL, Ross TF, Naughton JL. Myocardial ischemia and infarction related to recreational cocaine use. West J Med 1982; 136: 444-6.

4. Minor Jr RL, Scott BD, Brown DD, et al. Cocaine-induced myocardial infarction in patients with normal coronary arteries. Ann Intern Med 1991; 115: 797-806. 
5. Pitts WR, Lange RA, Cigarroa JE, et al. Cocaine-induced myocardial ischemia and infarction: pathophysiology, recognition, and management. Prog Cardiovasc Dis 1997; 40: 65-76.

6. Brogan III WC, Lange RA, Kim AS, et al. Alleviation of cocaine-induced coronary vasoconstriction by nitroglycerin. J Am Coll Cardiol 1991; 18: 581-6.

7. Kolodgie FD, Farb A, Virmani R. Pathobiological determinants of cocaine-associated cardiovascular syndromes. Hum Pathol 1995; 26: 583-6.

8. Kugelmass AD, Oda A, Monahan K, Cabral C, Ware JA. Activation of human platelets by cocaine. Circulation 1993; 88: 876-83.

9. Benzaquen BS, Cohen V, Eisenberg MJ. Effects of cocaine on the coronary arteries. Am Heart J 2001; 142: 402-10.

10. Hollander JE, Shih RD, Hoffman RS, et al. Predictors of coronary artery disease in patients with cocaine-associated myocardial infarction. Cocaine-Associated Myocardial Infarction (CAMI) Study Group. Am J Med 1997; 102: 158-63.

11. Lange RA, Hillis LD. Cardiovascular complications of cocaine use. N Engl J Med 2001; 345: 351-8.

12. Mittleman MA, Mintzer D, Maclure M, Toer GH, Sherwood JB, Muller JE. Triggering of myocardial infarction by cocaine. Circulation 1999; 99: 2737-41.

13. Roldan CA, Aliabadi D, Crawford MH. Prevalence of heart disease in asymptomatic chronic cocaine users. Cardiology 2001; 95: 25-30.

14. McCord J, Jneid H, Hollander JE, et al.; American Heart Association Acute Cardiac Care Committee of the Council on Clinical Cardiology. Management of cocaine-associated chest pain and myocardial infarction: a scientific statement from the American Heart Association Acute Cardiac Care Committee of the Council on Clinical Cardiology. Circulation 2008; 117: 1897-907

15. Singh S, Arora R, Khraisat A, et al. Increased incidence of in-stent thrombosis related to cocaine use: case series and review of literature. I Cardiovasc Pharmacol Ther 2007; 12: 298-303.

16. McKee SA, Applegate RJ, Hoyle JR, et al. Cocaine use is associated with an increased risk of stent thrombosis after percutaneous coronary intervention. Am Heart J 2007; 154: 159-64.

17. Makaryus JN, Volfson A, Azer V, Bogachuk E, Lee A. Acute stent thrombosis in the setting of cocaine abuse following percutaneous coronary intervention. J Interv Cardiol 2009; 22: 77-82.

18. Karlsson G, Rehman J, Kalaria V, Breall JA. Increased incidence of stent thrombosis in patients with cocaine use. Catheter Cardiovasc Interv 2007; 69: 955-8.

19. Halkin A, Singh M, Nikolsky E, et al. Prediction of mortality after primary percutaneous coronary intervention for acute myocardial infarction: the CADILLAC risk score. J Am Coll Cardiol 2005; 45: 1397-405. 